\title{
An Econometric Analysis of Trade, Culture and Healthcare Cooperation between China and Africa
}

\author{
EFFANGOU OTAMBOU Christ Mariel \\ School of Economics, Shandong University, Jinan, China \\ Email: christ.mariel@yahoo.com
}

\begin{abstract}
China has continuously strengthened and expanded its cooperation with Africa, its areas of intervention in the African continent are many and varied throughout the 2000's. After working hard to build strong bilateral relations by attributing political, trade and economic priorities, both partners have established strategic objectives with a view to promote the culture and healthcare cooperation. This paper examined the trade, culture and healthcare cooperation between China and Africa through the econometric analysis while taking into consideration all the African countries. The research used panel data and utilized the econometric model in assessing the impact of trade, culture and healthcare cooperation on African countries' economic growth. The panel data will cover 16 years (2003-2018). The secondary data was collected from the 54 African countries independently then made aggregates of the variable to represent Africa. The data were analyzed using SPSS software to get the descriptive statistics and regression of the economic growth (GDP) and (Imports, Exports, FDI, Culture and Healthcare). From the regression analysis, it can be affirmed that imports and exports have a positive and significant impact on the GDP. Then FDI has a negative and insignificant effect on economic growth; on the other hand, the culture and healthcare have a positive influence on African economy but insignificant and significant respectively. It can be affirmed that the econometric analysis of the Trade cooperation between China and Africa has affirmed that Imports and exports enhance the growth of African countries' economies. On the contrary, foreign direct investments have resulted in the exploitation of African human and capital resources for the benefit of a foreign country, which has a negative impact on economic growth.
\end{abstract}

Keywords: imports, exports, FDI, culture, healthcare, Africa, China

\section{Introduction}

After China's rise to the World Trade Organization in 2002, it has opened up to foreign trade investment and become one of the most attractive destinations for investment and global business. This boosted trade flows from China, which is now considered to be the lungs of the modern commercial world. It has been noted that Africa is one of the continents that have significantly developed a commercial partnership with the People's Republic of China, due to the mineral potential of Africa and manufactured goods of China. The high-level exchanges have become increasingly frequent for some time. This could include the systematic holding of international meetings, such as the Forum on ChinaAfrica Cooperation (FOCAC), which takes place every three years (since 2000 to date) whose one of the primary objectives is to strengthen the friendship and promote cooperation between both partners. However, it should also be stressed that the term "CHINAFRICA" causes conflicting opinions. Indeed, detractors of Chinese presence in Africa, attribute neo-colonialist ambitions to China by linking with economic imperialism dimension attached to "France-Africa".

Therefore, after a long period of politicalism, it was admitted that development is an overall process including a plurality of dimensions such as culture, education, healthcare and trade. Progress in the commercial trade was spectacular between the China and the African continent during the past fifteen years. According to the majority view in terms of money, the flows of merchandise trade have steeply increased from $\$ 20$ billion in 2003 to approximately $\$ 70$ billion in 2007. From 2010, trade transactions between China and Africa increased almost twofold and totaling around $\$ 124$ billion by the end of the year. The third FOCAC in Beijing in 2006 had set out an objective for raising trade up to $\$ 100$ billion 
at the end of 2010. Considered ambitious at the time, this objective was already surpassed in 2008 due to higher costs of some commodities and other products needed to support industrialization of China.

China is one of the Four Ancient Civilizations and Africa is the cradle of humanity, land that has rich culture; Chinese and African civilizations have made an invaluable contribution to human progress. Between 1334-1339, the Chinese explorer Wang Dayuan visited North Africa and East Africa. And under Ming dynasty, Zheng-He had allegedly visited East Africa during four of his seven famous voyages across the Indian Ocean. After these different contacts, exchanges between China and the African continent result in trading activities. Through cultural exchanges, China and Africa will move closer to each other, and then develop a mutual appreciation and a cordial attachment. Cultural and artistic promotion is one of the characteristics of new type of strategic partnership that has been put in place during the third FOCAC in 2006. Thanks to the common efforts of both parties, China-Africa cultural exchanges has taken a new turn. China establishes its first cultural centers in some African countries namely Mauritius, Egypt, Benin, etc. So despite all those events, the contribution of this culture cooperation on the economic front is still questioned. And this is also the case with health cooperation after several achievements. As part of this health cooperation, China has set up a partnership system with some African hospitals. The website of Chinese embassy in Burundi revealed that China has deployed more than 20,000 members from its medical corps in fifty African countries just for its medical missions abroad. So many health projects have been proposed and carried out for the well-being of two people. Those missions have played important role in improving overall medical and health standards in Africa, it also participated in the promotion of south-south cooperation and this associated to contribution of achievement of sustainable development goals.

This study considered the critical factors that help to strengthen the trade, culture and healthcare collaboration between Africa and China. In executing this, the study employed the econometric model to analyze the effect of trade collaboration between Africa and China on Africa's economic growth.

\section{Theoretical Analysis}

The econometric analysis of Trade Corporation indicates that imports, exports and FDIs have been increasing between China and Africa. This economic cooperation has also occurred in tandem with elevated cultural and healthcare interaction and integration between China and Africa (Abodohoui \& Su, 2020).

\subsection{Trade Cooperation between China and Africa}

Africa and China have a long tradition of trade which is decades old. The study by Okoro and Oyewole (2011) has ascertained that indeed there has been an upsurge of trade between China and Africa over several years. The trade cooperation between the two partners has received a more significant concern in the present decade as China's participation in trade and development growth has increased by double digits. Adewuyi et al. (2010) postulate that the Diplomatic ties between Africa and China can be traced back from the Ancient era through 1956 up to date. The study narrates the history between Africa and China trade cooperation existed over several years, and both trading partners have continued to have to get mutual benefits. Adewuiyi examined the cooperation policies of the two parties, especially the aim of the movement of China to the continent of Africa. The study concluded that China's entry to Africa was due to the search for energy security, profitable trade market and investments in the continent of Africa, and how to make use of under-utilized resources endowments in Africa. Okoro and Oyewole (2011) described the policy principle of the people's republic of China to their trade cooperation with the continent of Africa as an organized determination for a dual development and making use of resource capacities, which are accompanied by soft policies. Adewuyi et al. (2010) postulated that numerous African countries in present times, have had an incredible effort to enhance the relationship with the Chinese government and have significantly profited fully translating this into a more friendly business. The cooperation between China and Africa has led to both political and economic stability that never existed before. Many economic activities have been able to revive, and this has transformed their investment policies, bureaucratic obstacles, financial policies, and privatization in their many economies. The market products such as machines, food, clothes, agricultural implements, stationaries, transport 
equipment, and footwear, among other manufactured products are some of the trade components that are imported from China to Africa. On the same note, several raw materials such as oils, raw materials, and cash crops are exported from Africa to China. Some studies have made a comparison between developing countries and developed countries and found out that developing counties stand a higher chance to benefit from Bilateral trade than developed countries (Alshara, 2011). The study by Babatunde (2011) contributed to the expansion of comprehension of the degree with which the trade collaboration between Africa and China explained the development and economic growth in both regions.

\subsection{Culture Cooperation between China and Africa}

Consider Cultural cooperation as an important pillar in Sino-Africa relations; Secondary data collected from the China Internet Information Center (2013) shows that the cultural cooperation between China and Africa is a practice that has been on-going since the 1950s when China and Egypt ratified as cultural sharing. Since then, China has pursued cultural cooperation between nations such as Sudan, South Africa, and Kenya. The cross-cultural cooperation has been largely guided by China which has developed a variety of initiatives to help to underpin the cultural relations.

The cultural cooperation between Africa is demonstrated through a variety of channels. Firstly, events and activities with special themes focusing on culture are frequently held. The FOCAC Summits, Chinese Culture Month, and Moroccan Culture Week are quintessential cultural events that depict the improved cultural cooperation between China and Africa (Grimm, 2012; Brown \& Chun, 2009). This cooperation has also been demonstrated through cooperation in the training of performers and artists. Mayer et al. (2017) observe that African countries such as Tanzania have been sending academics and tutors to study and teach African culture and art in Chinese institutions. On the other hand, China has been training acrobats and gymnasts for African nations such as Sudan. To embolden this cooperation in art, exhibitions, mostly organized by China are held to help in showcasing African and Chinese artistry.

Migration and tourism have become important aspects of underpinning cultural cooperation between African nations and China. While Africa has largely lagged in attracting Chinese tourists, a report by The Hurun Research Institute and ILTM China, (2019) shows that tourism outflows, from China to Africa increased by $40 \%$ in the last five years. This increase is attributed to the Sino-African cultural cooperation which has improved in recent years. This argument is corroborated by data presented by The China Tourism Academy (2019) which indicates that the robust relationships between China and Africa have led to an influx of over 800,000 Chinese tourists in 2017 who toured various African countries.

Apart from cultural events and arts, cultural cooperation between China and Africa has been undertaken through the extensive presence of Chinese and African media. Batchelor and Zhang, (2017) report that mass media especially television and radio have been essential in promoting cultural exchanges between Africa and China. Due to the use of mass media, there has been an influx of Chinese pay-TV operators in Africa such as Star Times who showcase Chinese drama and film. The content is typically carried in African languages such as Swahili. Additionally, the surge in academic exchanges and academic cooperation between China and Africa has provided a robust channel where cultural exchanges occur (Mulinda, 2015). Contemporarily, only France beats China in the number of international students from Africa (King, 2020). This view is corroborated by Bodomo (2014) who asserts that many African students have moved to China to study with the number being boosted by scholarships being offered. Apart from scholarships, the proliferation of the Confucius Institutes in African countries and teaching of Chinese language and African languages in both regions has enabled students from China and Africa to collaborate in research and other academic disciplines. According to a report by UNESCO (2011, p. 13), these strategies have been followed by the expansion of Institutes of African Studies in many Chinese universities. Furthermore, the close educational ties help to foster a deeper understanding between Africa and China.

\subsection{Healthcare Cooperation between China and Africa}

Secondary data derived from Gao and Nkengasong (2019), indicates that social development cooperation between Africa and China has been on-going since 1963 when China sent 100 medical professionals to 
Algeria. Since then, healthcare has remained an important area where relations have been stepped up in the two regions leading to China being ranked in the top-ten of the bilateral donor list in matters relating to healthcare (Guillon \& Mathonnat, 2019).

Yang et al. (2018) observe that significant healthcare cooperation was boosted in 2006 after the Forum on China-Africa Cooperation (FOCAC) summit took place in Beijing. In the summit, resolutions set forth a framework on how Africa and China can cooperate in public health and medical care. The framework was based on the fact that many healthcare systems are saddled with limited health capabilities and high poverty levels. Additionally, healthcare systems have been subject to underfunding and neglect leading to a serious deviation from six pillars of healthcare delivery advanced by WHO. As a result, China has been stepping up its healthcare cooperation to help African countries in offsetting the adverse effects arising from these realities (Gao \& Nkengasong, 2019). For example, an action plan outlined by Forum on China-Africa Cooperation, (2018), indicates that there is a commitment by the Chinese government to construct Africa CDC to underpin public health initiatives in Africa. And, one strategy used to underpin healthcare cooperation is personnal training. The Chinese government has taken aggressive measures to help in bridging the gaps in skills and knowledge by undertaking robust training of medical professionals from Africa (Tambo et al. 2016). This strategy has been achieved through capacity-building initiatives that have enabled African students to receive scholarships and grants to train and study in Chinese medical institutions.

China has taken a leading role in developing health infrastructure in Africa. Lin et al. (2016) observe that China has been involved in financing healthcare development through grants and concessional loans. This financial cooperation is expected to continue in 2019-2021 as outlined by (Forum on China-Africa Cooperation, 2018). The report indicates that the Chinese government will provide concessional loans, interest-free loans, and grants of up to US\$15 billion to boost health in Africa. Apart from erecting new hospitals, China has supported the continent in healthcare through technology transfers.

The cooperation to fight pandemics is also captured in the commitment by Africa and China to augment their quarantine collaborations through training of African professionals as well as harmonizing the working of Regional Collaboration Centers (RCCs), African Centre for Disease Control and Prevention (Africa CDC) with Chinese health institutions to help in combating highly infectious diseases (Forum on China-Africa Cooperation, 2018). Aside from this, the Forum on China-Africa Cooperation (2018), notes that China is involved in constructing health facilities in different African countries.

\section{Literature Review}

Many studies have been made concerning the issue of the impact of trade on economic growth. A good number of studies have confirmed that there is a positive and significant association between trade and commercial trade (Babatunde, 2011; Bhattacharya \& Das, 2014). Babatunde (2011) surveyed the connection between openness and growth by combining multiple policy criteria (monopolization of exports, non-tariff and tariff measures, state export monopolies, and black-market exchange rate premium) all aggregated to one control variable and categorizing nations either as closed or open. The research showed that openness had a strong and positive association with growth as changes in the openness index accounted for about two percent annual economic growth for the period of 1970 -1989. Hoque and Yusop (2010) used the index of openness as an indication of frankness alongside other models totaling several trade protection measures to detect when liberalization happened. The research discovered in the long-term, the increment of liberalization was two percent and the economic openness was $50 \%$ richer than closed economies as a form of GDP per capita. However, it was noted that in the short-run, liberalization negatively affects the growth in the initial year then has a positive effect in subsequent years. The favorable business environment present in African has been affirmed to be one of the main reasons for the continent of Africa (Biyase \& Zwane, 2011). Nevertheless, the findings by Kurihara (2013) affirm the opinion that the high inflation rate has a negative impact on FDI and Trade inflows. Additionally, the imbalances of some microeconomic basics in Africa have been significant determiners and have negatively affected the access to continuous investment and inflow of trade among the continents. The constant increase in the exchange rate and inflation rate among African countries 
have changed investment and trade. War and corruption have influenced trade inflows and investments in African Countries.

There are a wide variety of studies that have been conducted to explore the issue of cultural cooperation between China and Africa (Abodohoui \& Su, 2020). However, there is limited consensus on when cultural cooperation started. A study by Grimm (2012) considers the formation of the Forum on China-Africa Cooperation (FOCAC) as the major event that led to contemporary cultural cooperation. This view is contrasted by the China Internet Information Center (2013) which views cultural cooperation between China and Africa as a process that commenced in the 1950s when China established close cultural ties with Egypt. Despite having being attributed to conflicting histories; literature by Mayer et al. (2017) and Mulinda (2015) have a similar observation which indicates that cultural cooperation between China and Africa has been strengthened in recent years. This view is corroborated by Monson and Rupp (2013) who show that an influx of African students into China has fueled cultural cooperation. This view is contested by The Hurun Research Institute and ILTM China, (2019) who assert that increasing outflows of Chinese tourists has been central to the development of cultural cooperation. However, it is imperative to note that the studies by The Hurun Research Institute and ILTM China, (2019) and Monson and Rupp (2013) do not feature well-defined methodologies hence, their validity is contested. On the other hand, primary research conducted by Batchelor and Zhang, (2017) indicates that mass communication projected from China has been at the forefront of underpinning cultural cooperation.

There are different studies evaluating health cooperation between China and Africa. In a study conducted by Lin et al. (2016), literature shows health cooperation between Africa and China has been postured as a sustainable development goal. These sustainable goals in health have been pursued differently across different nations. However, most of the objectives have been encompassed in the FOCAC Beijing Action Plan (2019-21). Researches with similar results conducted by Aninpah \& Menjo (2008) and Pokam (2011) indicate that health cooperation has been underpinned by establishing Chinese health Infrastructure into the continent. This evidence has also been shown in central Africa in a study conducted by Somé et al. (2019). The study shows that China has focused on providing finances through loans and grants to facilitate the construction of health facilities. Despite China having strong healthcare cooperation, the exact reasons for cooperation are not pursued in studies. In a study by Tambo et al (2016) it is shown that "agricultural production, to food auto-sufficiency value chain and productivity of employees". This aspect has been corroborated by those who assert that health cooperation is being used to underpin economic growth. Lange \& Vollmer (2017) also argue that the desire of many Africa nations to enhance their child and maternal health, there has been an increase in health cooperation.

\section{Data and Methodology}

Various components affect economic growth as a result of trade, culture and healthcare cooperation between China and Africa. The key variables that affect the economy of any country are imports, exports, and foreign direct investment. The paper examines the effect of the three above mentioned variables, then culture and healthcare on economic growth using the econometric method. The data and methodology are as follows:

To explicate the impact of imports on the growth of the economy in African continent as a result of trade cooperation between China and Africa; Autoregressive model is used, and sample data will be from 2003 to 2018. The period was selected due to the limitation of the availability of data on Foreign Direct Investments, which started increasing steadily since 2003. Thus, the analysis will be done on all the African countries that have been trading with China. The empirical study will use the annual timeseries secondary data being collected from independent countries and aggregate made per year to represent Africa. In any research study, data reliability is a critical issue. Most of the African countries do not have a strong database system due to archival data problems that have faced the continent in the past. Therefore, careful attention was devoted while compiling the data in the excel file. All these sources of data are acknowledged and have widely been used in the respective countries. Therefore, the data and information given from the sources that were consequently incorporated in the analysis are reliable. 


\section{The Econometric Model}

The study explains the effect of imports, exports, Foreign Direct Investment, culture and healthcare on the economic growth of the whole of Africa. In the model, the explanatory variables are Imports (IMP), Exports $(E X P)$, Foreign Direct Investment $(F D I)$, Culture $(C)$, and Healthcare $(H)$. The dependent variable is Economic growth measured in $G D P(Y)$, which has various indices such as trade liberalization, import liberalization, reduction of anti-export, among other indices. Considering Cobb-Douglas production function, the model can be represented as follows:

$$
\begin{gathered}
Y=\beta_{0}^{1} . I M P_{t}^{\beta_{1}} E X P_{t}^{\beta_{2}} F D I_{t}^{\beta_{3}} \\
Y=\beta_{0}^{1} . I M P_{t}^{\beta_{1}} E X P_{t}^{\beta_{2}} F D I_{t}^{\beta_{3}} C_{t}^{\beta_{4}} H_{t}^{\beta_{5}}
\end{gathered}
$$

After transforming all variables, the Lin-log form of the model (2) can be written as follows:

$$
\operatorname{Ln}(Y)=\beta_{0}+\beta_{1} \operatorname{Ln}\left(I M P_{t}\right)+\beta_{2} \operatorname{Ln}\left(E X P_{t}\right)+\beta_{3} \operatorname{Ln}\left(F D I_{t}\right)+\beta_{4}(C)+\beta_{5}(H)+\mu_{t}
$$

It is important to note that:

$$
\begin{aligned}
& \mu_{t} \text { represents the error term with an indication of time. } \\
& \beta_{0}=\operatorname{Ln} \beta_{0}^{1} \\
& C \text { and } H \text { are considered as dummy variables. }
\end{aligned}
$$

The expected sign of the estimated coefficients

1. $\beta_{0}>0$; since if the exports increase, then the economic growth must increase i.e., the relationship between exports, imports, and Foreign Direct Investment are positive.

2. $\beta_{1}>0$; since Africa is made up of developing countries, if $G D P\left(Y_{t}\right)$ increases more than the increase in imports, the GDP decreases, and this means that the relationship between GDP and imports is negative.

\section{Econometric Analysis}

The model and data sources have been discussed in the previous section. The model is the autoregressive model which is a Lin-log function, as shown below:

$$
\operatorname{Ln}(Y)=\beta_{0}+\beta_{1} \operatorname{Ln}\left(I M P_{t}\right)+\beta_{2} \operatorname{Ln}\left(E X P_{t}\right)+\beta_{3} \operatorname{Ln}\left(F D I_{t}\right)+\beta_{4}(C)+\beta_{5}(H)+\mu_{t}
$$

We took the logarithm of all the explanatory variables by using the econometric program SPSS; and, after that, we ran the Ordinary Least Square (OLS) method.

\section{Results and Discussions}

Table 1. Aggregate trade cooperation between China-Africa from 2003 to 2018

\begin{tabular}{ccccc}
\hline & Imports $(\$ \mathrm{M})$ & Export $(\$ \mathrm{M})$ & FDI $(\$ \mathrm{M})$ & GDP $\$$ M \\
\hline 2003 & $7,409.09$ & $10,124.76$ & 310.79 & 64921.84 \\
2004 & $13,740.25$ & $13,729.95$ & 713.75 & 78683.28 \\
2005 & $18,987.40$ & $18,602.94$ & 1393.29 & 92858.97 \\
2006 & $26,794.39$ & $26,583.92$ & 2242.81 & 102872.77 \\
2007 & $33,911.46$ & $37,373.32$ & 3973.32 & 116587.00 \\
2008 & $51,041.51$ & $51,089.01$ & 7092.5 & 139338.39 \\
2009 & $40,306.93$ & $59,807.45$ & 8388.55 & 120285.74 \\
2010 & $60,265.67$ & $47,635.11$ & 11963.85 & 134631.67 \\
2011 & $73,634.16$ & $72,919.40$ & 14468.04 & 145600.23 \\
2012 & $78,911.07$ & $85,133.66$ & 18856.93 & 152429.74 \\
2013 & $81,113.19$ & $92,570.97$ & 22500.62 & 154628.04 \\
2014 & $79,858.53$ & $94,499.21$ & 38584.71 & 150313.24 \\
2015 & $47,526.79$ & $105,832.84$ & 40814.25 & 126754.08 \\
2016 & $41,273.03$ & $155,695.57$ & 32350.07 & 120529.56 \\
2017 & $60,210.01$ & $91,984.61$ & 34694.4 & 128999.76 \\
2018 & $80,336.63$ & $104,949.33$ & 39877.47 & 134968.05 \\
\hline
\end{tabular}




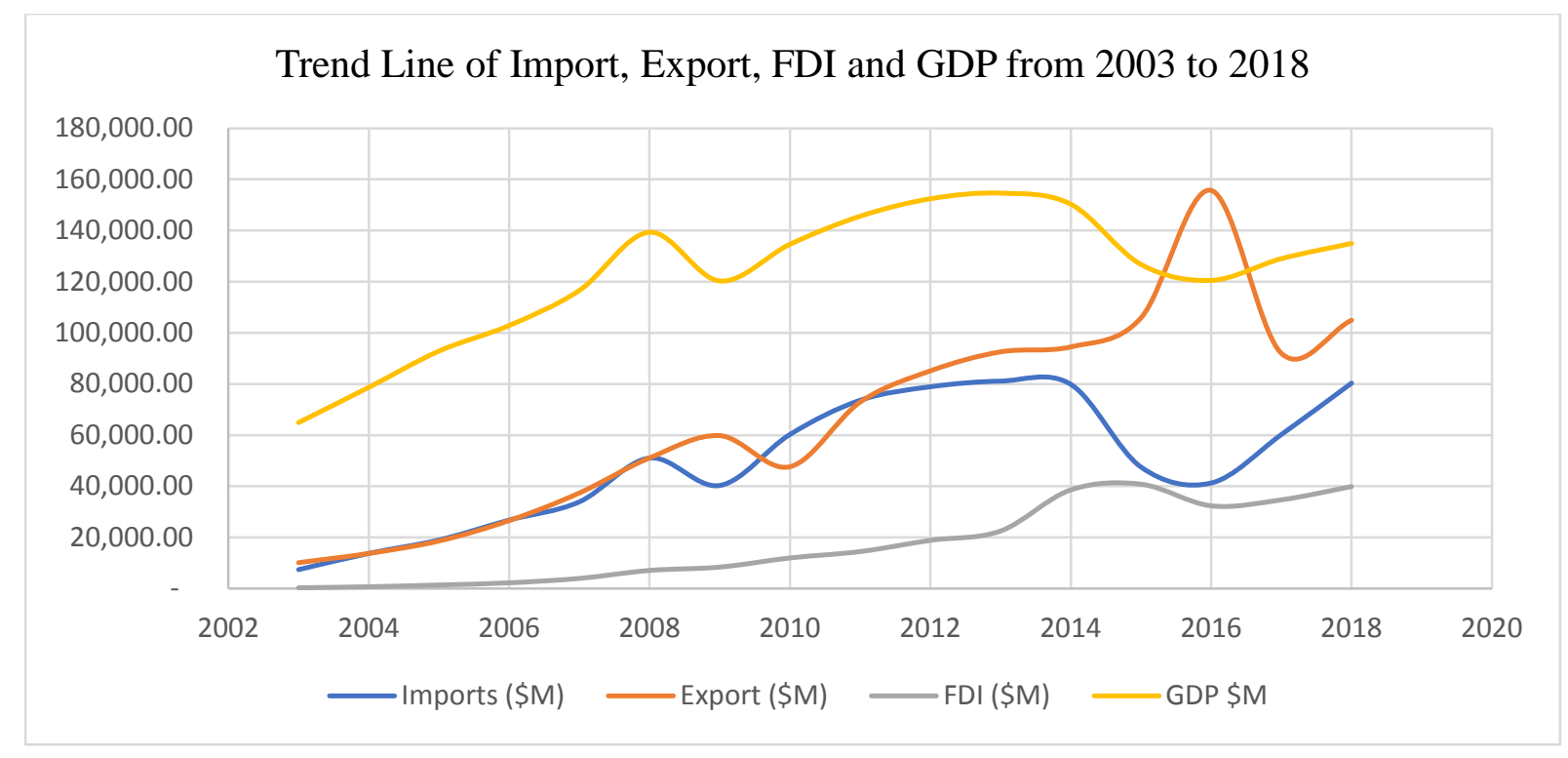

Figure 1. The trend of trade between China and Africa from 2003 to 2018

From the trend above, it can be exhibited that the imports from Africa to China have been increasing at an increasing rate from 2003 , whereby the imports were $\$ 7,409.09 \mathrm{M}$ and reached an optimum level in 2013 where the aggregate imports were $\$ 81,113.19$. Subsequently, the imports decreased sharply to $\$ 41,273.03 \mathrm{M}$, which was the lowest since 2010 . The decrease in imports is attributed to the unfavorable movement of exchange rates where most of the African currencies depreciated against the dollar. This means that the imports were costly due to the high demand of the African currencies as compared to foreign currency.

The exports have been increasing since 2003, where the total exports for the continent were $\$ 10,124.76$. The exports grew at an increasing rate reaching its highest export level in 2016, where the aggregate export was $\$ 155,695.57$. This shows that the trade cooperation between China and Africa has opened the international market for African products, and this has resulted in an improvement of economic growth due to an increase in the revenue, employment and stability of the African countries' currencies.

The foreign direct investment started in the year 2003, and it has since been scaling up with time. In the year 2013, the aggregate FDI was 310.79M; however, by the year 2014, the FDI had reached $40814.25 \mathrm{M}$, meaning that the stakes have been growing and resulting in more investments in Africa. This is a positive impact of the trade cooperation that has been experienced between the two trading partners.

The aggregate Gross Domestic Product (GDP) for the continent has been increasing steadily since 2003 after the Chinese company started its Foreign Direct Investment in Africa. The GDP grew at an increasing rate and reached its highest amount in 2013 at $\$ 154628.04 \mathrm{M}$. After that, the GDP for the continent started to decrease at a slower pace due to political risk, unfavorable movement in exchange rates, inflation, and an increase in the interest rates.

Descriptive Statistics

\begin{tabular}{c|ccccc}
\hline & $\mathrm{N}$ & Minimum & Maximum & Mean & Std. Deviation \\
\hline Imports & 864 & 7409.09 & 81113.19 & 49707.51 & 25096.82 \\
Export & 864 & 10124.76 & 155695.57 & 66783.25 & 40676.23 \\
FDI & 864 & 310.79 & 40814.25 & 17389.08 & 15308.59 \\
GDP & 864 & 64921.84 & 154628.04 & 122775.15 & 26360.59 \\
Valid N (listwise) & 864 & & & & \\
\hline
\end{tabular}




\section{Regression Analysis}

\begin{tabular}{c|cccc}
\multicolumn{5}{c}{ Model Summary } \\
\hline Model & $\mathrm{R}$ & R Square & Adjusted R Square & Std. Error of the Estimate \\
\hline 1 & $0.989^{\mathrm{a}}$ & 0.978 & 0.973 & 0.01757 \\
\hline \multicolumn{2}{l}{ a. Predictors: (Constant), FDI, Imports, Exports }
\end{tabular}

The model has an $\mathrm{R}$ square of 0.978 which translates to $97.8 \%$. This means that the changes in the economic growth (GDP) are explained by $97.5 \%$ of the changes in Imports, export and Foreign direct investments and the remaining percentage is explained by other factors. It therefore, means that the model is reliable and it produces significant results.

\begin{tabular}{cc|ccccc}
\hline & Model & Sum of Squares & Df & Mean Square & F & Sig. \\
\hline 1 & Regression & 0.168 & 3 & 0.056 & 181.915 & $0.000^{\mathrm{b}}$ \\
& Residual & 0.004 & 12 & 0.000 & & \\
& Total & 0.172 & 15 & & & \\
\hline
\end{tabular}

a. Dependent Variable: GDP

b. Predictors: (Constant), FDI, Imports, Exports

Coefficients $^{\mathrm{a}}$

\begin{tabular}{|c|c|c|c|c|c|c|}
\hline & \multirow[b]{2}{*}{ Model } & \multicolumn{2}{|c|}{ Unstandardized Coefficients } & \multirow{2}{*}{$\begin{array}{c}\text { Standardized Coefficients } \\
\text { Beta } \\
\end{array}$} & \multirow[b]{2}{*}{$\mathrm{T}$} & \multirow[b]{2}{*}{ Sig. } \\
\hline & & $\mathrm{B}$ & Std. Error & & & \\
\hline \multirow[t]{4}{*}{1} & (Constant) & 3.032 & 0.234 & & 12.960 & 0.000 \\
\hline & Imports & 0.395 & 0.038 & 1.126 & 10.506 & 0.000 \\
\hline & Exports & 0.116 & 0.067 & 0.378 & 1.723 & 0.111 \\
\hline & FDI & -0.083 & 0.041 & -0.518 & -2.015 & 0.067 \\
\hline
\end{tabular}

a. Dependent Variable: GDP

The regression analysis results exhibit that import and export have a positive association with the Gross Domestic Product. Imports have a standardized beta of 1.126, with a significance level of 0.000 . This means that a unit rise in the imports results in an increase in the Gross domestic product by 1.126. This signifies that the trade cooperation between China and Africa has a positive influence on the African Countries, whereby most of the countries benefit from the imports from China, which enhance their GDP. The increase in GDP results in price stability, an increase in employment rate, and stability in currency. Therefore, it can be affirmed that imports have momentous and positive effects on GDP.

The exports have a positive beta of 0.378 and a significance of 0.000 , meaning that it has a positive and material impact on the Gross Domestic Product. The trade collaboration between China and Africa has opened a market for African products. The increase in the demand for the products means that the African countries export their goods and, in return, get the foreign currency, which boosts their Gross National Product. The trade cooperation between the African continent is beneficial to most African countries, which are mostly developing countries.

Foreign direct investment has been noted to have a negative impact on the Gross Domestic Product. The beta for FDI is -0.5518 and has a significant of 0.067 , which means that though it has a negative relationship with the GDP, its effect is insignificant. Though foreign direct investments create employment for the local people, most of the revenues from such operations go to the parent companies which are domiciled in China. It, therefore, increases the revenue to the Chinese company that it generates for the African countries. Since most African countries depend on loans, they service loans through interests, which reduces the available funds for infrastructure and development. 


\section{Regression Analysis}

Model Summary

\begin{tabular}{c|cccc}
\hline Model & $\mathrm{R}$ & $\mathrm{R}$ Square & Adjusted R Square & Std. Error of the Estimate \\
\hline 1 & $0.33^{\mathrm{a}}$ & 0.109 & -0.070 & 0.1108 \\
\hline
\end{tabular}

The model has an $\mathrm{R}$ square of 0.330 which translates to $10.9 \%$. This means that the changes in the economic growth (GDP) are explained by $10.9 \%$ of the changes in the culture. The remaining percentage is explained by other variables which are not included in the model.

Coefficients $^{\mathrm{a}}$

\begin{tabular}{|c|c|c|c|c|c|c|}
\hline \multirow{2}{*}{\multicolumn{2}{|c|}{ Model }} & \multicolumn{2}{|c|}{ Unstandardized Coefficients } & \multirow{2}{*}{$\begin{array}{c}\text { Standardized Coefficients } \\
\text { Beta }\end{array}$} & \multirow[b]{2}{*}{ t } & \multirow[b]{2}{*}{ Sig. } \\
\hline & & $\mathrm{B}$ & Std. Error & & & \\
\hline 1 & (Constant) & 5.074 & 0.042 & & 121.115 & 0.000 \\
\hline & Culture & 0.007 & 0.056 & 0.033 & 0.123 & 0.904 \\
\hline
\end{tabular}

a. Dependent Variable: GDP\$M

The regression analysis shows that the correlation between culture and economic growth is 0.056 with a significance level of 0.904 . Since the significance level is more than the threshold of 0.05 at 95 confidential intervals, it can be affirmed that it is statistically insignificant. This means that there exists a positive but insignificant correlation between healthcare and economic growth. This means that a unit change in culture results to a 0.033 change in the economic growth. Since it is insignificant, it cannot be considered as a factor that can affect the economic growth of Africa as a whole.

\section{Regression Analysis}

Model Summary

\begin{tabular}{c|cccc}
\hline Model & R & R Square & Adjusted R Square & Std. Error of the Estimate \\
\hline 1 & $0.791^{\mathrm{a}}$ & 0.625 & 0.441 & 0.0801 \\
\hline
\end{tabular}

a. Predictors: (Constant), HC

The model has an $\mathrm{R}$ square of 0.625 which translates to $62.5 \%$. This means that the changes in the economic growth (GDP) are explained by $62.5 \%$ of the changes in the healthcare. The remaining percentage is explained by other variables which are not included in the model.

Coefficients $^{\mathrm{a}}$

\begin{tabular}{|c|c|c|c|c|c|c|}
\hline & \multirow[b]{2}{*}{ Model } & \multicolumn{2}{|c|}{ Unstandardized Coefficients } & \multirow{2}{*}{$\begin{array}{c}\text { Standardized Coefficients } \\
\text { Beta }\end{array}$} & \multirow[b]{2}{*}{$\mathrm{t}$} & \multirow[b]{2}{*}{ Sig. } \\
\hline & & $\mathrm{B}$ & Std. Error & & & \\
\hline \multirow[t]{2}{*}{1} & (Constant) & 3.198 & 0.526 & & 6.085 & 0.000 \\
\hline & $\mathrm{HC}$ & 1.006 & 0.281 & 0.691 & 3.580 & 0.003 \\
\hline
\end{tabular}

a. Dependent Variable: GDP\$M

The regression analysis shows that the correlation between healthcare and economic growth is 0.691 with a significance level of 0.003. Since the significance level is less than the threshold of 0.05 at 95 confidential intervals, it can be affirmed that it is statistically significant. This means that there exists a positive and strong correlation between healthcare and economic growth. This means that a unit change in healthcare results to a 0.691 change in the economic growth. 


\section{Conclusion}

The paper has comprehensively and candidly investigated the impact of trade, culture and healthcare cooperation between China and Africa on economic growth. It is affirmed that FDI flows from the China government play a critical role in the development of African countries. Africa's export to China has a positive and material effect on growth in economy. The export of resources to China has increased due to the ever-rising demand for raw materials. This is, however, attributed to positive vicissitudes in terms of trade that has enhanced cooperation between China and Africa. Non-resource low-cost goods imported from China have benefited African consumers. This has as well helped African producers who import low-cost intermediate products from China. Besides, the healthcare services have a positive and significant impact to the economic growth. China has been involved in financing healthcare development through grants and concessional loans. Healthy people have the energy to work in various firms and institutions that produce goods and services. The goods and services are sold or rendered at a fee hence generating a significant amount of revenue to the African countries. This consequently leads to the advancement of economy of the African countries. On the other hand, the culture has a positive but insignificant impact to the economic growth. Culture help people from different countries to be conversant with other people's way of lives to minimize the culture shock. However, this positive impact does not majorly contribute to the growth of economy.

Foreign direct investment has been an entry mode for most Chinese companies to Africa, and their post-entry operations have led to the manufacturing of more goods and services and development of infrastructures, which have led to the increase in economic growth. However, African countries should focus on the attraction of Foreign Direct Investment efficiency to create a favorable environment for the private sector. The provision of a favorable environment can be made through; provision of a transparent and more uncomplicated regulatory environment, upgrading and building new infrastructures, tax exemptions, and establishment of more economic zones to enhance trading cooperation between Africa and China. Additionally, the positive effects of foreign investments should be harnessed by African governments. Improvement of linkages between the domestic economy and international firms is pertinent in improving the growth impacts of foreign investment. African countries should also target certain industries that are vital for development of the economy, and sufficiently devote overseas investments to these respective segments of the economy. This strategy will increase the productive capacity and local investments, boosting local levels of employment, and fostering the integration of African firms to form a vast global economy. Fundamentally, the right combination of the regional policy and framework should be done to significantly increase the Foreign Direct Investment flows and increase the spillover effects.

\section{References}

1. http://bi.chineseembassy.org/fra/ChineRegardBurundais/t1627918.htm

2. http://www.sais-cari.org/other-data

3. Abodohoui, A, \& Su, Z. (2020). Influence of Chinese managerial soft power on African skills development. International Business Review, 101730.

4. Okoro, E, \& Oyewole, P. (2011). A cost-benefit analysis of China's trade relations with sub-Saharan Africa. Chinese Business Review, 10(9).

5. Adewuyi, A. O, Alarudeen, A., \& Kareem, O. I. (2010). Impact of China-Africa trade relations: The case of Nigeria.

6. Alshara, A. (2011). The Impact of cooperation and partnership agreements on the values of Arab inter-trade (Master Thesis). Institute of Economics and Commerce SciencesAcademic Center in Ghardaia-Algeria.

7. Babatunde, A. (2011). Trade Openness, Infrastructure, FDI and Growth in Sub-Saharan African Countries. Journal of Management Policy \& Practice, 12(7).

8. China Internet Information Center, 2013. Cultural Exchange Between China and Africa. [Online] Available at: HYPERLINK. http://www.china.org.cn/english/features/China-Africa/82031.htm

9. Grimm, S. (2012). The Forum on China-Africa Cooperation (FOCAC)-Political rationale and functioning.

10. Brown, K., \& Chun, Z. (2009). China in Africa-Preparing for the next forum for China Africa cooperation. Asia Programme Briefing Note ASP2009/02. Chatham House. London. 
11. Claude-Hélène Mayer, Christian M. Boness \& Lynette Louw (2017, July). Chinese managers' views on cooperating with Tanzanian employees in a Chinese organisation in Dar-Es-Salaam, Tanzania. In Poster presentation at the European Congress of Psychology, Amsterdam, The Netherlands (pp. 11-14).

12. The Hurun Research Institute and ILTM China, 2019. The Chinese Luxury Traveller. Beijing: ILTM China.

13. The China Tourism Academy, 2019. Annual Report on China Outbound Tourism Development 2019. Beijing: CTA.

14. Batchelor, K., \& Zhang, X. (Eds.). (2017). China-Africa Relations: Building Images Through Cultural Cooperation, Media Representation, and Communication. Taylor \& Francis.

15. Mulinda, C. K. (2015). On Cultural and Academic Exchanges between China and African Countries. International Journal of Asian Social Science, 5(4), 245-256.

16. King, K. (2020). China-Africa Education Cooperation: From FOCAC to Belt and Road. ECNU Review of Education, 3(2), 221-234.

17. Bodomo, A. (2014, September). Africans in China: The experiences from education and training. In The International Conference of China and Africa Media, Communications and Public Diplomacy, Beijing (pp. 1011).

18. UNESCO, October 2011. Report on the Development of ChinaAfrica Educational Cooperation

19. Gao, G. F. \& Nkengasong, J. N. (2019). Public health priorities for China-Africa cooperation. The Lancet Public Health, 4(4), e177-e178.

20. Guillon M. \& Mathonnat J. (2019). Is there a strategy in China's health official development assistance to African countries? Revue d'économie politique,129(4), 619-660.

21. Yang H. M., Liu P. L. \& Guo Y. (2018). Determinants of China's development assistance for health at the subnational level of African countries (2006-2015). Infectious diseases of poverty, 7(1), 128.

22. Forum on China-Africa Cooperation Beijing Action Plan (2019-2021).

23. Ernest Tamb, Chidiebere E Ugwu, Yayi Guan, Ding Wei, Xiao Ning \& Zhou Xiao-Nong (2016). China-Africa Health Development Initiatives: benefits and implications for shaping innovative and evidence-informed national health policies and programs in sub-Saharan African countries. International Journal of MCH and AIDS, 5(2), 119.

24. Shuang Lin, Liangmin Gao, Melissa Reyes, Feng Cheng, Joan Kaufman \& Wafaa M. El-Sadr (2018). China's health assistance to Africa: opportunism or altruism? Globalization and Health 14(1). DOI: 10.1186/s12992-0180411-4

25. Bhattacharya, S. K. \& Das, G. G. (2014). Can South-South trade agreements reduce development deficits? An exploration of SAARC during 1995-2008. Journal of South Asian Development, 9(3), 253-285.

26. Pokam, H. D. P. (2011). Chinese medicine in Cameroon. China Perspectives, 2011(2011/3), 51-58

27. Exploring the impact of healthcare on economic growth in africa. J Somé, S Pasali, M Kaboine - Applied Economics and Finance, 2019

28. Lange S. \& Vollmer S. (2017). The effect of economic development on population health: a review of the empirical evidence. British medical bulletin, 121(1), 47-60. 